\title{
Effects of Slurry Properties on the Crack Formation in Ceramic Green Sheets during Drying
}

\author{
Takamasa MORI, Tomofumi YAMADA, Tatsuya TANAKA, Akiko KATAGIRI and JunIchiro TSUBAKI \\ Department of Molecular Design and Engineering, Nagoya University, Furo-cho, Chikusa-ku, Nagoya-shi $464-8603$
}

\author{
テープ成形体乾燥時の亀裂発生に及ぼすスラリー特性の影響 \\ 森＼cjkstart隆昌－山田朋文－田中達也·片桐亜希子·椿 淳一郎 \\ 名古屋大学大学院工学研究科, 464-8603 名古屋市千種区不老町
}

\begin{abstract}
The slurries studied were characterized by a conventional apparent viscosity measurement, a constant rate filtration and a stress relaxation test proposed in this study in order to identify the most affective property of a slurry on the crack formation of a green sheet during drying. We evaluated the packing ability of the slurry from the constant rate filtration and stress relaxation rate of a cake form by the stress relaxation test. Slurries were also tape cast, dried at room temperature and then cracks formed in green sheets were observed. Slurry properties were controlled by changing the $\mathrm{pH}$ value of the slurry or the additive amount of the binder. It was shown that there is not a good correlation between the apparent viscosity, packing ability of slurry and crack formation in the green sheet, while the number of cracks decreased with an increase in the stress relaxation rate of the cake. The stress relaxation test can be useful to predict crack formation during drying regardless of the slurry preparation method such as the $\mathrm{pH}$ adjusted or binder containing slurries.
\end{abstract}

[Received July 12, 2006; Accepted August 24, 2006]

Key-words : Tape casting, Crack formation, Constant rate filtration, Stress relaxation, Stress relaxation rate

1. Introduction

A paper-thin, flexible green sheets of various ceramic compositions are produced by tape casting for the manufacturing of substrates of electronic conductors, resistors, and multilayer capacitors. This forming process has the following advantages: (i) easy control of the thickness of the green sheets, (ii) easy handling and processing of the green sheets, and (iii) able to laminate the green sheets. However, shape distortion and/ or cracking often occurs during drying, causing defects of the final products. ${ }^{1)-4)}$ Because the volatility and toxicity of organic solvents used in slurries are harmful to the environment and health, and the solvents are difficult to recycle, the aqueous tape casting has been widely studied. ${ }^{5-23)}$ Water, as a solvent, has the advantage of being non-toxic, non-flammable, easily available and cheap. Nevertheless, aqueous tape casting is still not widely adopted by this industry because the probability of a crack formation in green sheets is much higher, as compared to using an organic solvent.

The properties of the green sheets strongly depend on the slurry properties, however, the relationship between the slurry properties, the crack formation during drying and the optimal slurry conditions are still unknown and are usually determined by trial and error. ${ }^{5)-11)}$ In various research concerning the slurry characterization for tape casting, ${ }^{12)}{ }^{19)}$ the apparent viscosity of the slurry was used to evaluate the slurry property in an ordinary way, even though it does not have a good correlation with the drying behavior of green sheets, such as crack formation and critical cracking thickness.

During drying, the drying stress occurs in a green sheet because of the capillary force and initiates the cracking. ${ }^{1,3), 20)-23)}$ Therefore, the following two factors of the slurry should affect the crack formation.

Firstly, if particles in a green sheet were packed very closely and particles could not move easily, the green sheet endures the drying stress, resulting in a crack free green sheet. In this case we can predict the crack formation from the density of the green sheet. It was reported that the density of green bodies are influenced by the packing ability of the slurry, ${ }^{24)-28)}$ therefore, the crack formation is expected to have a close relation to the packing ability of the slurry.

Secondly, if the drying stress dispersed and decreased quickly, cracking should not occur. In this case we can predict the crack formation by measuring the stress relaxation rate of the green sheet.

The aims of this study were to identify the most affecting property of the slurry on the drying behavior of a green sheet and to establish the general slurry characterization method for the tape casting process. From the above viewpoint, the particle packing ability and the stress relaxation rate were evaluated by the constant rate filtration and stress relaxation test.

\subsection{Slurry preparation}

We used two types of slurries: one was a $\mathrm{pH}$ adjusted slurry and the other was the binder containing slurry.

\section{$2.2 \mathrm{pH}$ adjusted slurries}

Slurries were prepared from the alumina powder (AES-11E with an average particle size of $0.48 \mu \mathrm{m}$, Sumitomo Chemical) and distilled water by the ball-milling technique for $2 \mathrm{~h}$ using alumina balls in a polyethylene bottle. A solution of hydrochloric acid was used to control the $\mathrm{pH}$ values of the slurries. The $\mathrm{pH}$ values of slurries were $3.1,3.7,3.8,3.9$, and 5.4 in this study. Initial solid concentration was $45 \mathrm{vol} \%$. The prepared slurries were degassed by a vacuum treatment and then used for the slurry characterization and the tape casting test.

2.3 Binder containing slurries

The raw material was also the alumina powder and polycarboxylic ammoniun (D-305, Chukyo Yushi) and was used as a dispersant. Polyvinyl alcohols (PVA) and polyethyleneglycol (PEG) were used as a binder and a plasticizer, respectively. 


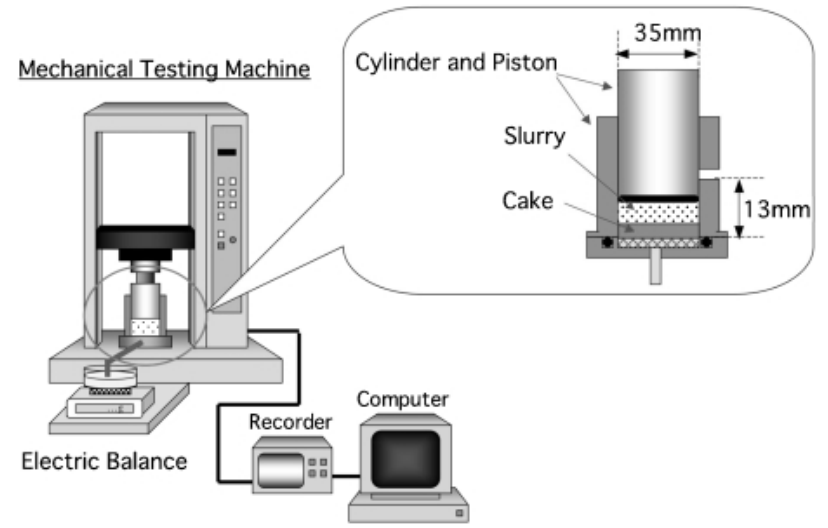

Fig. 1. Experimental apparatus for the constant rate filtration and stress relaxation test.

The initial solid concentration was 35 vol\%. Firstly, alumina powder, distilled water and the dispersant were mixed by ballmilling for $1 \mathrm{~h}$. After ball-milling, the prepared slurries were degassed and poured into a container. The PEG was added gradually into the slurries under stirring and then the PVA was added subsequently. The total amount of the PVA and the PEG changed from $4,5,6$, and $7 \mathrm{vol} \%$, while the ratio of the PVA and the PEG was $1: 1$ for all slurries.

\subsection{Slurry characterization}

The prepared slurries were characterized by an apparent viscosity measurement, a constant rate filtration and a stress relaxation test. The apparent viscosity was measured by a Brookfield type viscometer (BK type, Tokimec Inc.) at a shear rate of $7.3 \mathrm{~s}^{-1}$.

Figure 1 shows the schematic illustration of the experimental apparatus for the constant rate filtration and the stress relaxation test. The prepared slurry was poured into the filtration equipment and placed on the mechanical testing machine (SDW-2000, Imada Co.). Then, the filtration was started by moving the piston down at a constant speed of $0.14 \mathrm{~mm}$ per $\min ^{-1}$. After the filtration, the formed cake was compressed until the stress reached at $1 \mathrm{MPa}$, and then the valve at the bottom of the filtration equipment was closed and the strain of the cake was maintained at the same pressure. The stress relaxation behavior was observed until the stress became almost constant. For the binder containing slurries, the maximum stress was changed to $3 \mathrm{MPa}$, because the filtration did not complete when the stress reached $1 \mathrm{MPa}$.

\subsection{Tape casting}

Figure 2 shows the schematic illustration of the tape casting equipment used in this study. A gap of $0.5 \mathrm{~mm}$ under the blade and a casting speed of $145 \mathrm{~mm}$ per min were selected for all the casting tests. The green sheet obtained from this experiment had $170 \mathrm{~mm}$ width and $500 \mathrm{~mm}$ length. The cast tape dried at room temperature for at least $15 \mathrm{~h}$. The career sheet with cast green sheet was fixed on a table in order to prevent the distortion of it.

After drying, we observed the crack formation in green sheets by a digital camera. In order to evaluate the cracks, we drew lines with a distance of $30 \mathrm{~mm}$ as shown in Fig. 3 and counted the number of intersections between the cracks and the lines. The number of cracks was determined by dividing the number of intersections by the total length of all the lines, which means the number of intersections between the cracks and the lines at unit length of the line. (I don't understand this "...the lines at unit length of the line")

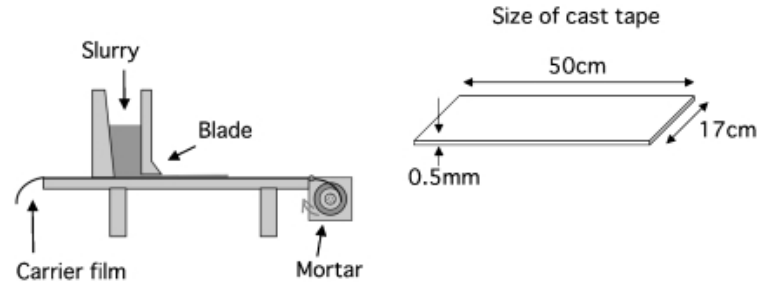

Fig. 2. Experimental apparatus for tape casting.

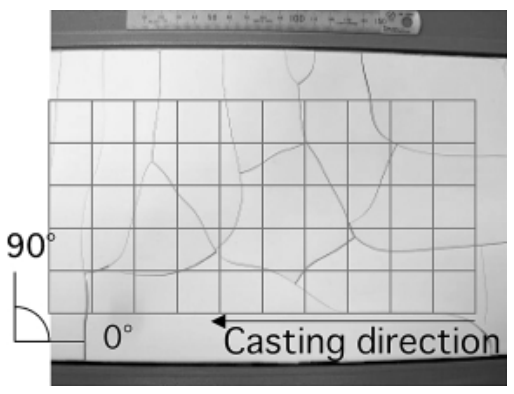

Fig. 3. Definition of the number of cracks.

Table 1. Packing Fraction of the Cake for $\mathrm{pH}$ Adjusted Slurries

\begin{tabular}{cc}
\hline Sample & $\begin{array}{c}\text { Packing fraction } \\
{[-]}\end{array}$ \\
\hline pH3.1 & 0.49 \\
pH3.7 & 0.49 \\
pH3.8 & 0.49 \\
pH3.9 & 0.48 \\
pH5.4 & 0.46 \\
\hline
\end{tabular}

\section{Results and discussion}

\subsection{Slurry characterization}

The packing fraction of the formed cake after filtration was calculated from the filtrate $v$ and cake height $L$, using the following mass balance equation.

$$
\Phi=\frac{v+L}{L} \phi_{0}
$$

The packing fractions of the cake are summarized in Table 1 for the $\mathrm{pH}$ adjusted slurries. Only for the slurry with a $\mathrm{pH}$ of 5.4 , the packing fraction was relatively low, while the others had almost the same value. Figure 4 shows the stress relaxation behavior of the formed cake for the $\mathrm{pH}$ adjusted slurries. In order to characterize these stress relaxation curves, the stress relaxation rate defined by the following equation was introduced (Fig. 5).

$$
(\text { Stress Relaxation Rate })=\frac{(\text { Relaxation Stress })}{(\text { Relaxation Time })}
$$

The stress relaxation rates are summarized in Table 2 for the $\mathrm{pH}$ adjusted slurries. The stress relaxation rate increased with a decrease in the $\mathrm{pH}$ value of slurry and the maximum stress relaxation rate was obtained for the slurry with a $\mathrm{pH}$ of 3.1.

The packing fractions of the formed cake after filtration and the stress relaxation rate are summarized in Table 3 for 


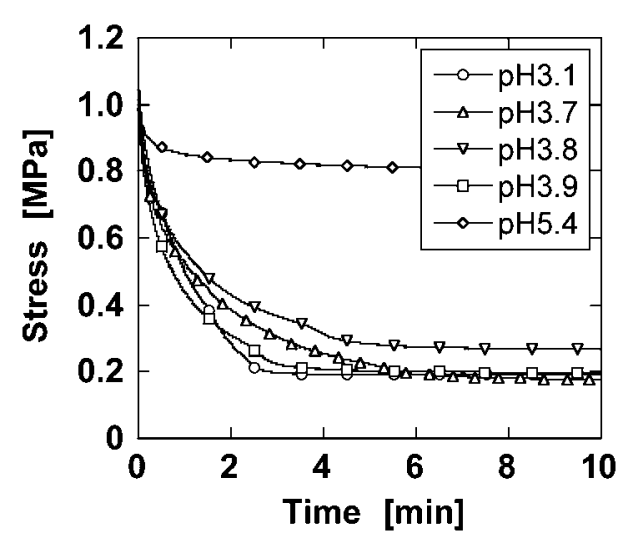

Fig. 4. Time changes of stress acting on the cake.

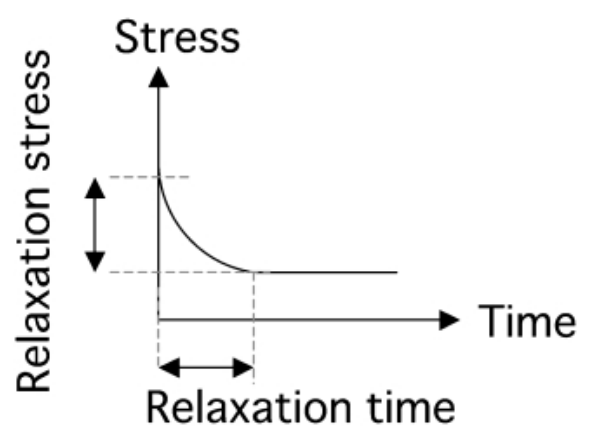

Fig. 5. Schematic diagram of stress relaxation behavior.

Table 2. Relaxation Rate for $\mathrm{pH}$ Adjusted Slurries

\begin{tabular}{cc}
\hline Sample & $\begin{array}{c}\text { Relaxation rate } \\
{\left[\mathrm{kPa} \cdot \mathrm{s}^{-1}\right]}\end{array}$ \\
\hline $\mathrm{pH} 3.1$ & 4.7 \\
$\mathrm{pH} 3.7$ & 1.6 \\
$\mathrm{pH} 3.8$ & 2.0 \\
$\mathrm{pH} 3.9$ & 3.1 \\
$\mathrm{pH} 5.4$ & 0.11 \\
\hline
\end{tabular}

Table 3. Packing Fraction of the Cake and Relaxation Rate for Binder Containing Slurries

\begin{tabular}{ccc}
\hline Sample & $\begin{array}{c}\text { Packing fraction } \\
{[-]}\end{array}$ & $\begin{array}{c}\text { Relaxation rate } \\
{\left[\mathrm{kPa} \cdot \mathrm{s}^{-1}\right]}\end{array}$ \\
\hline 4 & 0.57 & 0.81 \\
5 & 0.62 & 1.2 \\
6 & 0.63 & 1.4 \\
7 & 0.56 & 5.0 \\
8 & 0.54 & 5.1 \\
\hline
\end{tabular}

(a)

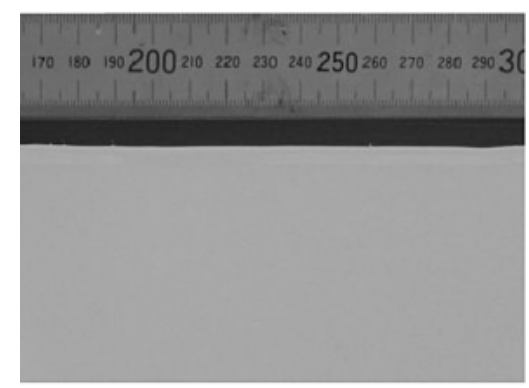

(b)

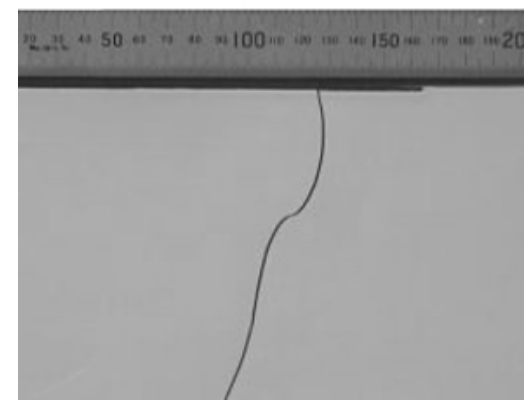

Fig. 6. Photographs of cast tape obtained from $\mathrm{pH}$ adjusted slurries, (a) $\mathrm{pH} 3.1$ and (b) $\mathrm{pH} 3.8$.

the binder containing slurries. We couldnot find a clear pattern about the packing fraction of the cake for the binder containing slurries. In general, the stress relaxation increased with total amount of additives.

\subsection{Characterization of green sheets}

Figures 6 and 7 show the examples of the cast sheets obtained from the $\mathrm{pH}$ adjusted slurries and the binder containing slurries. The number of cracks is summarized in Tables $\mathbf{4}$ and 5. For the pH adjusted slurries, we could obtain crack free green sheets from the slurry with a $\mathrm{pH}$ of 3.1. On the other hand, the green sheets obtained from the slurry with a $\mathrm{pH}$ of 5.8 had many cracks and the number of cracks was quite large when compared to the others.

For binder containing slurries, we could obtain crack free sheets from the slurries with a relatively large amount of additives. Unfortunately, degassing was difficult for the slurries with a large amount of additives because the viscosity of the slurry was high, resulting in very small defects at the surface of the green sheet. However, we will eliminate these defects by improving the degassing method, therefore we neglected these defects for the calculation of the number of the cracks.

3.3 Relationship between slurry properties and crack formation apparent viscosity

Figure 8 shows the relationship between the apparent viscosity of the prepared slurries and the number of cracks. It was shown that there is not a good correlation between the apparent viscosity and the number of cracks. Also, the apparent viscosity changed to almost three times larger, even though the number of cracks remained zero. From these results, it is difficult to predict the crack formation in the green sheet from the apparent viscosity as shown in previous reports. ${ }^{19)}$

3.4 Packing fraction of the cake

Figures 9 and $\mathbf{1 0}$ show the relationship between the packing fraction of the cake obtained from the filtration and the number of cracks. Here, because the maximum applied pressure 
(a)

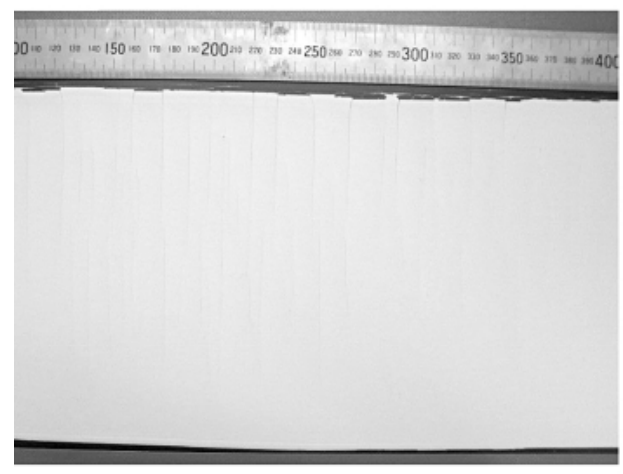

(b)

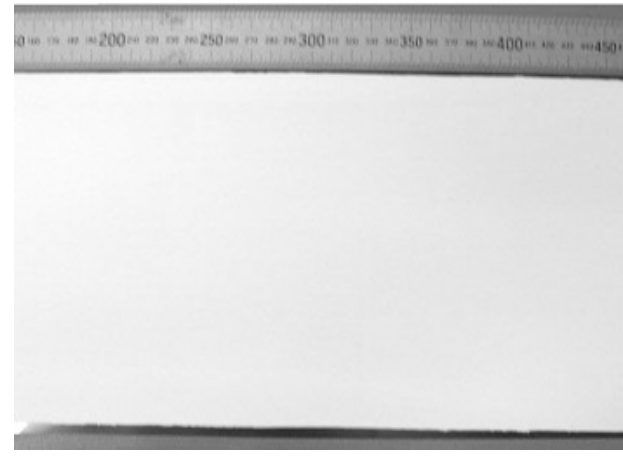

Fig. 7. Photographs of the cast tape obtained from binder containing slurries, (a) 4 vol\% and (b) 8 vol\%.

Table 4. Number of Cracks for $\mathrm{pH}$ Adjusted Slurries

\begin{tabular}{cc}
\hline Sample & $\begin{array}{c}\text { Number of cracks } \\
{\left[\mathrm{m}^{1}\right]}\end{array}$ \\
\hline $\mathrm{pH} 3.1$ & 0 \\
$\mathrm{pH} 3.7$ & 7.0 \\
$\mathrm{pH} 3.8$ & 2.2 \\
$\mathrm{pH} 3.9$ & 2.1 \\
$\mathrm{pH} 5.4$ & 57 \\
\hline
\end{tabular}

Table 5. Number of Cracks for Binder Containing Slurries

\begin{tabular}{cc} 
Sample & $\begin{array}{c}\text { Number of cracks } \\
{\left[\mathrm{m}^{1}\right]}\end{array}$ \\
\hline 4 & 21 \\
5 & 6.1 \\
6 & 2.9 \\
7 & 0 \\
8 & 0 \\
\hline
\end{tabular}

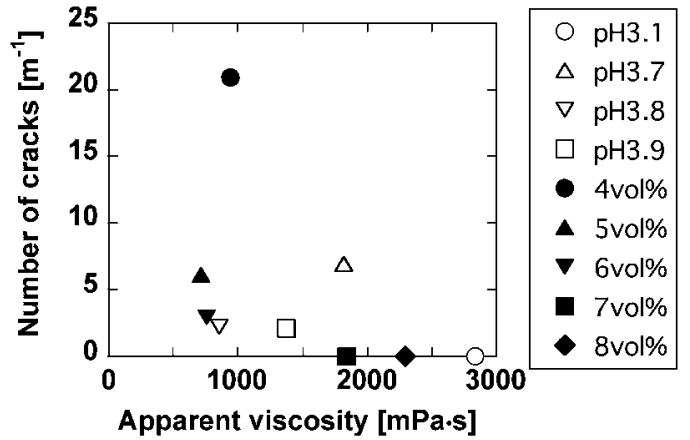

Fig. 8. Relationship between the number of cracks and apparent viscosity.
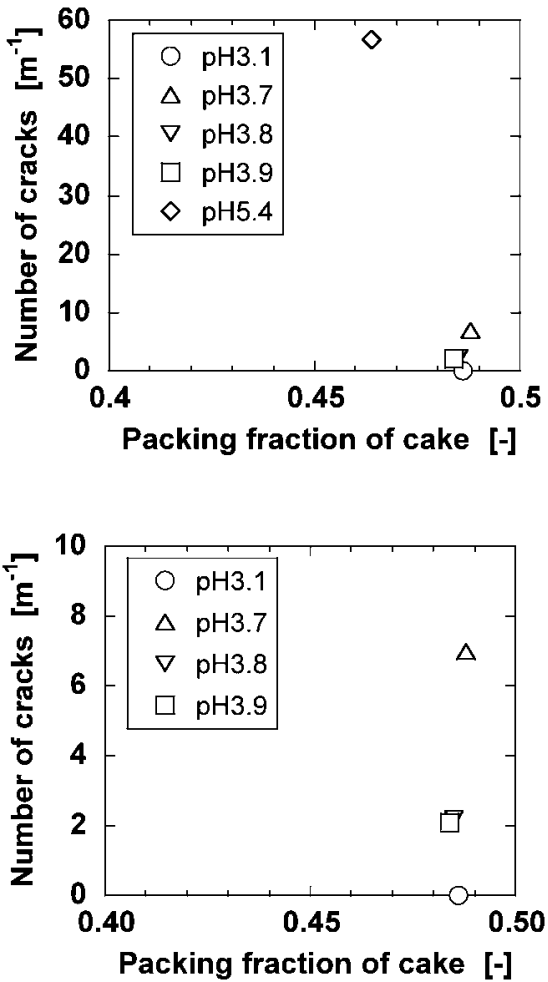

Fig. 9. Relationship between the number of cracks and packing fraction of cake for $\mathrm{pH}$ adjusted slurries.

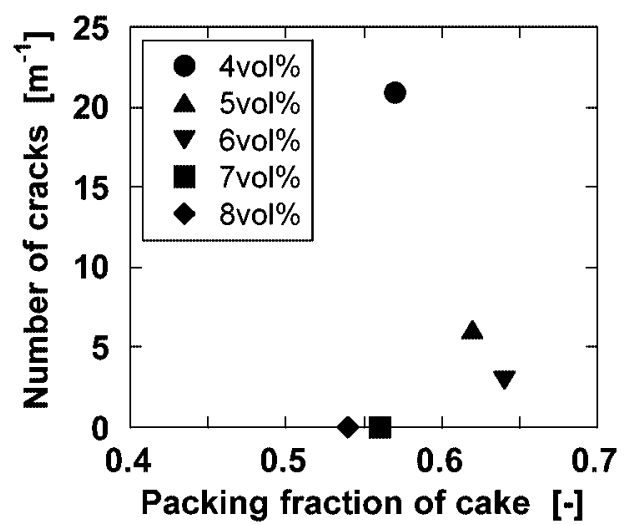

Fig. 10. Relationship between the number of cracks and packing fraction of cake for binder containing slurries. 

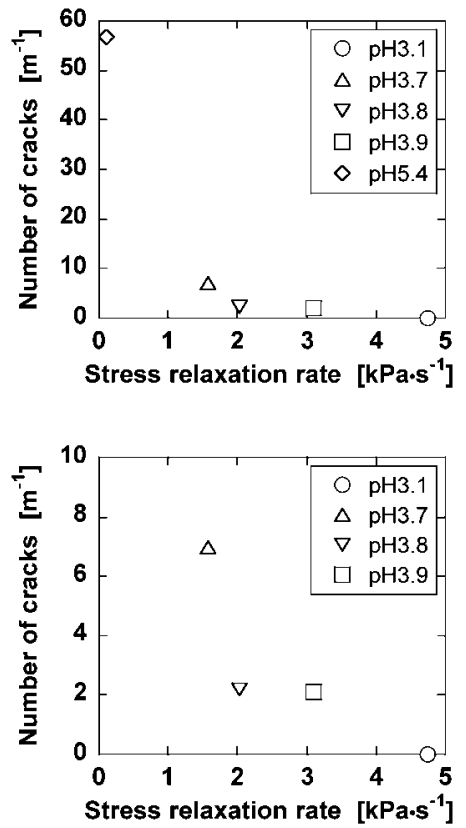

Fig. 11. Relationship between the number of cracks and stress relaxation rate for $\mathrm{pH}$ adjusted slurries.

was different, we discuss the results of the $\mathrm{pH}$ adjusted slurries and the binder containing slurries, separately.

For the $\mathrm{pH}$ adjusted slurries, broadly speaking, the number of cracks would decrease with an increase in the packing fraction of the cake. However, there was little difference between the packing fractions of the slurries with a pH of 3.1, (crack free) 3.8 and 3.9 (a few cracks). This means that we can not predict the crack formation strictly from the packing fraction of the cake for $\mathrm{pH}$ adjusted slurries.

For binder containing slurries, there was no clear relation between the packing fraction of the cake obtained by the filtration and the number of cracks.

In previous reports, ${ }^{29), 30)}$ researchers discussed the relation of the crack formation and the packing ability of slurry, however, the results were quite different. Some researchers said that the films obtained from a flocculate slurry have few cracks because the flocculate slurry made a film with a loose packing of particles, namely due to the lowering the capillary force during drying, while others said that the coating cast from more flocculated slurry cracked earlier. From the above discussion, the packing fraction of the cake should not be the main factor affecting on the crack formation in green sheets.

\subsection{Stress relaxation rate}

Figures 11 and 12 show the relationship between the stress relaxation rate and the number of cracks for the $\mathrm{pH}$ adjusted slurries and the binder containing slurries, respectively. It was found that the number of cracks decreased with an increase of the stress relaxation rate for both slurries. In addition, there was a clear difference between the slurries making crack free green sheets and the green sheets with a few cracks, while it was hard to distinguish them from the apparent viscosity of the slurry or the packing fraction of the cake. These results suggest that the drying stress should be released quickly in the case of the slurry with a higher stress relaxation rate, resulting in a crack free green sheet, as mentioned in the introduction of this paper. After all, the most affecting factor on the crack formation in the green sheets must be the stress relaxation rate as the stress relaxation test can be useful to predict crack for-

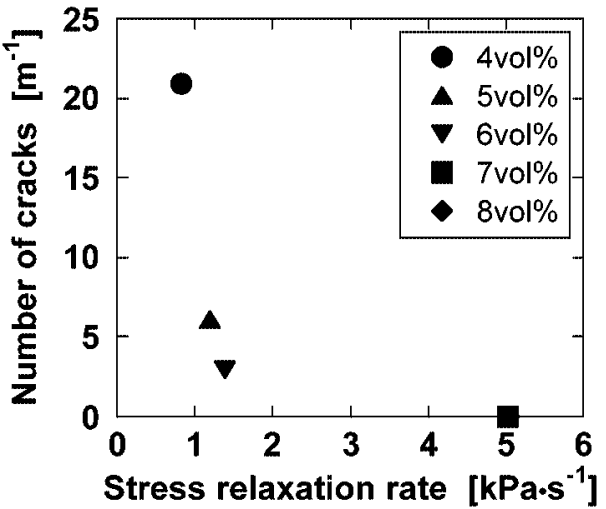

Fig. 12. Relationship between the number of cracks and stress relaxation rate for binder containing slurries.

mations during drying regardless of the slurry preparation method.

\section{Conclusion}

In order to identify the most affecting property of the slurry on the drying behavior of a green sheet, some slurry characterizations including the novel stress relaxation test and tape casting were conducted. It was shown that the number of cracks decreased with an increase in the stress relaxation rate, and the stress relaxation rate had the closest relation to the number of cracks among all the slurry properties measured in this study. The stress relaxation test can be useful to predict crack formations during drying regardless of the slurry preparation method such as $\mathrm{pH}$ adjusted or binder containing slurries.

Acknowledgement The authors would like to acknowledge the financial support of Hosokawa Powder Technology Foundation, Japan.

Noritake Company Ltd. is acknowledged for providing the apparatus for tape casting.

\section{Nomenclature}

$\Phi$ : packing fraction of the cake

$\phi_{0}:$ initial solid volumetric concentration

$L$ : cake height

$v$ : volume of filtrate in unit area

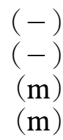

\section{References}

1) Reed, J. S., Principles of Ceramics Processing, pp. 525-539 (1995).

2) Mizutani, N., Kimura, T., Ozaki, Y. and Yamaguchi, T., Ceramic Processing, pp. 119-121 (1987).

3) Scherer, G. W., J. Am. Ceram. Soc., Vol. 73(1), pp. 3-14 (1990).

4) Misra, R., Barker, A. J. and East, J., Chem. Eng. Journal, Vol. 86, pp. 111-116 (2002).

5) Albano, M. P. and Garrido, L. B., Mater. Sci. Eng. A, Vol. 420, pp. 171-178 (2006).

6) Gurauskis, J., Sanchez-Herencia, A. J. and Baudin, C., J. Eur. Ceram. Soc., Vol. 25, pp. 3403-3411 (2005).

7) Mei, S., Yang, J., Xu, X., Quaresma, S., Agathopoulos, S. and Ferreira, J. M., J. Eur. Ceram. Soc., Vol. 26, pp. 67-71 (2006).

8) Navarro, A., Alcock, J. R. and Whatmore, R. W., J. Eur. Ceram. Soc., Vol. 24, pp. 1073-1076 (2004).

9) Snijkers, F., Wilde, A., Mullens, S. and Luyten, J., J. Eur. Ceram. Soc., Vol. 24, pp. 1107-1110 (2004).

10) Kristoffersson, A. Roncari, E. and Galassi, C., J. Eur. Ceram. Soc., Vol. 18, pp. 2123-2131 (1998). 
11) Descamps, M., Ringuet, G., Leger, D. and Thierry, B., J. Eur. Ceram. Soc., Vol. 15, pp. 357-362 (1995).

12) Albano, M. P. and Garrido, L. B., Ceram. Inter., Vol. 32(5), pp. 567-574 (2006).

13) Song, Y. L., Liu, X. L., Zhang, J. Q., Zou, X. Y. and Chen, J. F., Powder Technol., Vol. 155, pp. 26-32 (2005).

14) Olhero, S. M. and Ferreira, J. M., J. Mater. Proc. Technol., Vol. 169, pp. 206-213 (2005).

15) Jingxian, Z., Dongliang, J., Weisensel, L. and Greil, P., J. Eur. Ceram. Soc., Vol. 24, pp. 2259-2265 (2004).

16) Seal, A., Chattopadhyay, D., Sharma, A. D., Sen, A. and Maiti, H. S., J. Eur. Ceram. Soc., Vol. 24, pp. 2275-2283 (2004).

17) Yuping, Z., Dongliang, J. and Greil, P., J. Eur. Ceram. Soc., Vol. 20, pp. 1691-1697 (2000).

18) Kristoffersson, A., Lapasin, R. and Galassi, C., J. Eur. Ceram. Soc., Vol. 18, pp. 2133-2140 (1998).

19) Greenwood, R., Roncari, E. and Galassi, C., J. Eur. Ceram. Soc., Vol. 17, pp. 1393-1401 (1997).

20) Kiennemann, J., Chartier, T., Pagnoux, C., Baumard, J. F., Huger, M. and Lamerant, J. M., J. Eur. Ceram. Soc., Vol. 25, pp. 1551-1564 (2005).

21) Wedin, P., Lewis, J. A. and Bergstrom, L., J. Colloid Interface Sci., Vol. 290, pp. 134-144 (2005).

22) Martinez, C. J. and Lewis, J. A., J. Am. Ceram. Soc., Vol. 85, pp. 2409-2416 (2002).

23) Lewis, J. A., Blackman, K. A. and Ogden, A. L., J. Am. Ceram. Soc., Vol. 79, pp. 3225-3234 (1996).

24) Mori, T., Kuno, K., Ito, M., Tsubaki, J. and Sakurai, T., Adv. Powder Technol., Vol. 17 (2006) in press.

25) Mori, T., Kim, H., Ato, K. and Tsubaki, J., J. Ceram. Soc. Japan, Vol. 114, pp. 318-322 (2006).

26) Sakamoto, W. and Hirano, S., Mater. Integration, Vol. 19, pp. 25-33 (2006).

27) Bertrand, G., Filiatre, C., Mahdjoub, H., Foissy, A. and Coddet, C., J. Eur. Ceram. Soc., Vol. 23, pp. 263-271 (2003).

28) Tsubaki, J., Kato, M., Miyazawa, M., Kuma, T. and Mori, H. J. Chem. Eng. Sci., Vol. 56, pp. 3021-3026 (2001).

29) Chiu, R. C., Garino, T. J. and Cima, M. J., J. Am. Ceram. Soc., Vol. 76, pp. 2257-2264 (1993).

30) Lan, W., Wang, X. and Xiao, P., J. Eur. Ceram. Soc. (2006) in press. 